\title{
AN EXCELLENT MYSTERY OR JUST ANOTHER FINE MESS?
}

\section{Brian Childs, Senior Lecturer in Law, Queen's University Belfast}

The British building industry, or at least that section of it which undertakes repairs and improvements to domestic residential property, enjoys an unenviable reputation for delay, dishonesty and incompetence. ${ }^{1}$ This must be extremely galling for the majority of plumbers, electricians and installers of double-glazing who try to, and usually do, provide a decent service at a reasonable price to their customers. But however unfair such honest tradesmen may feel is the reputation which has attached itself to their industry, and by implication to themselves, it can hardly be denied that the blame for this state of affairs lies at the door of those in the industry who have too often spectacularly failed to meet the most basic standards of fair trading. When a roof repairer is caught on camera "removing" a squirrel's dray from a householder's roof - an item which he has himself been filmed placing in position only a few moments earlier - and then explaining to the householder the extensive remedial work that this "squirrel invasion" will require, it is rather difficult for the industry's defenders to maintain with any plausibility that there is no evidence to justify concern. ${ }^{2}$

However at least the legal position of the householder who has the misfortune to become embroiled with one of these black sheep of the industry is not really in any doubt if the householder actually commissions the work. ${ }^{3}$ The more blatant scams are likely to be criminal anyway, while incompetently performed work, or work not carried out when it should have been, will usually involve a breach of contract and a tort as well in any case in which additional damage is caused by defective or insufficiently skilled workmanship. The fact that such legal rights exist does not, of course, necessarily mean that using them will be either easy or even advisable given

1 In the year ending 30 September 2000 there were 70,736 complaints recorded by the Office of Fair Trading in the category "home maintenance, repairs and improvements", and a further 28,211 in the category "double glazing products and installation". These figures reveal that complaints have now caught up with those for second hand cars [72,944 recorded complaints, with a further 28,032 in respect of repairs and servicing in 2000] which for years were comfortably ahead as a source of consumer dissatisfaction. Such figures are likely to represent only the tip of the iceberg. See the Annual Report of the Office of Fair Trading 2000.

2 This incident, along with a number of equally disturbing examples, was shown in the World in Action programme transmitted on Monday 27 October 1997.

3 There can be little doubt that this subject is one of the Cinderella subjects of the law. Despite the frequency of complaints (supra $\mathrm{n} 1$ ), the topic is conspicuous by its absence from most legal texts. The majority of books on consumer law ignore it, even though taken in conjunction with the similar antics of the domestic appliance repairing fraternity, complaints about incompetently performed and/or excessively priced repair work constitute one of, if not the, most significant source $(s)$ of consumer dissatisfaction. A search against the headings "Property repairs" and "Defective premises" conducted in the indexes of the major works on consumer law produced few results, nor did turning to works on land law produce a discernible improvement in the situation. 
the fragile solvency of many of the firms making up the domestic repairs and home improvements sector. Obtaining another unenforceable judgment to add to the record is really of little comfort to the householder and is not recommended. But at least the commissioning householder can ascertain the legal position in advance and be advised of any possible measures that may be taken to safeguard it, for example, making sure that there is a signed written record of what was agreed to be done so as to provide unequivocal evidence of the express terms of the resulting contract should any dispute arise. Furthermore the commissioning householder can avail of such useful preventative strategies as making enquiries about the financial stability of a firm whose services it is proposed to engage, or asking to be provided with the names of people for whom work has previously been done who can be asked about the extent of their satisfaction (or otherwise) with it. It would be ridiculous to claim that the situation is perfect, or that there is no scope for improvement, but at least there is no significant doubt about what rights the householder is supposed to enjoy.

However, when we turn to the situation of the householder who has occasion to claim the cost of repairing ${ }^{4}$ damage from his or her property insurers a somewhat different picture presents itself, at least in those situations where the insurance company engages the services of a loss adjuster who then deals directly with the contractor carrying out the repairs. ${ }^{5}$ In such a situation the

4 For convenience the terms "repairing" and "repairs" will be employed throughout to embrace not only such genuine repairs as replacing broken guttering or unblocking drains but also (where the context requires it) home improvements, such as installing double glazing or central heating, and periodic maintenance, such as replumbing and rewiring. Improvements and routine maintenance are matters not covered by any normal insurance policy so that almost invariably the householder will have made a contract directly with the builder and thus not be of concern to us. However, hybrid situations can arise where advantage is taken of the fact that circumstances necessitating repairs have arisen in order to effect improvements to the property. Obviously such situations are capable of producing interesting demarcation disputes as to whose business the contractor was engaged on (and thus to whom he had contractual responsibilities) at the relevant time when the "damage" was being caused.

5 The problems remain basically the same should the insurer decide to dispense with the services of a loss adjuster and itself deal directly with the contractor, although obviously the involvement of fewer parties reduces the number of possible permutations. The exact extent to which insurers do make use of the services of loss adjusters is information which does not appear to be readily available but the practice is certainly not unusual in the context of property repairs. By contrast, the practice seems far less common in the case of vehicle repairs - the other principal area in which a consumer is likely to be having repair work done which will be paid for by insurance. The reason for this is not known but a possible explanation is that in the case of vehicle repairs there is far less scope for negotiation about the scope of required repairs and the method to be adopted. A car with a damaged door will need a replacement door specific to that make and model of car: in the case of a house with a damaged door the range of choices is much wider, and there is also a much greater possibility of the same level of service being available at a variety of prices. Thus there is a stronger chance of an advantageous deal being struck, advantageous that is from the insurer's point of view. Against this has to be placed the piece of folk wisdom that any repairer who knows that the costs of the work are to be met by an insurer immediately increases the estimate substantially. It is not easy to discover how widespread this practice actually is but the writer has 
householder is unlikely to have any say in the selection of the contractor, ${ }^{6}$ and thus no opportunity to make the enquiries necessary to forestall engaging the services of someone with a past record for ineptitude or dishonesty. Furthermore, in a situation where the contractor is engaged by the loss adjusters to whom he will look for payment, it is not exactly obvious that there is any contractual relationship between the householder and the person performing the work. Certainly in the scenario envisaged it would be unlikely in the extreme that the householder would have much of an input into the express terms of the contract: these would be the result of the dealings that passed between the loss adjuster and the contractor. But the inexorable logic of a situation where this is what happens is that there is no direct contractual relationship at all and the consequent absence of privity means that the householder is equally unable to place any reliance on implied terms such as, for example, those contained in sections 13 - 15 of the Supply of Goods and Services Act 1982. ${ }^{7}$ Of course, absence of privity is no obstacle to a claim in tort, and there is little doubt that contractors undertaking work on the property of another owe to that other a duty of care, but the extent of the protection this is likely to afford is really quite limited. True it may be that establishing liability is unlikely to be a problem where the activities of the contractor result in personal injury or further damage to the property but such situations will not be typical: indeed, any property damage is far more likely to present itself in the form of exceeding what is actually necessary to effect the repairs when proper care and skill are used rather than in the form of damage to a clearly separate item of property totally unconnected with the task in hand. Most property repair work inevitably generates some damage in the course of carrying it out - for just as the surgeon cannot remove the appendix without making an incision, so the glazing contractor cannot replace the window without making some mess consequently the argument is likely to be about how far, if at all, unnecessary

personally encountered it on more than one occasion and can thus testify to the fact that it is not entirely mythical.

6 For the sake of simplicity the term "contractor" will be used throughout to refer to the person or firm undertaking the repairs whatever the particular specialism involved. References to "the contractor" etc should be read accordingly unless the contrary is stated.

7 The Contracts (Rights of Third Parties) Act 1999 will not affect this situation in any significant way since it does not oblige contracting parties to confer enforceable rights on third parties but, on the contrary, expressly permits them to exclude any possibility of third party enforcement (s1(2)). Hence, while in situations where the main objective of the contract is to provide a benefit to the third party, of which Tweddle v Atkinson (1861) 1 B \& S 393 provides the most celebrated example, it may be expected that the Act will be utilised, it certainly does not follow that its possibilities will be invoked in the sort of situation where the objective of the actual contracting parties is to provide a service to the third party in the way which maximises, in so far as legitimately possible, the benefit to themselves. In other words, in the sort of situation envisaged by this article, when the concern of the loss adjuster will be to keep the cost of the work down to the minimum that is consonant with honouring the terms of the insurance cover under which it is being paid for, and when the concern of the contractor will be to ensure that profit margins are maintained, there is no discernible reason why either party should see any advantage to be gained from conferring enforceable third party rights on the householder. It will therefore not be done. 
disruption and damage have been caused. This type of scenario sits much more easily in the contractual context of reasonable care and skill than in the tortious one, ${ }^{8}$ since it more closely resembles a claim for substandard workmanship than it does one for actually causing identifiable physical damage. ${ }^{9}$ And, of course, where the complaint is simply of poorly done work which has harmed nothing as yet, apart, perhaps, from the value of the householder's property, ${ }^{10}$ then the claim is one for pure economic loss and thus almost certainly irrecoverable in tort unless the facts allow the case to be squeezed within the rather uncertain exception for expenditure necessary to avert a clear and present danger to adjoining property or to users of the highway. ${ }^{11}$ Nor are the difficulties with identifying remedies in contract or

8 It is tempting to explain why this is so in terms of the distinction between the essentially positive nature of contractual duties and the essentially negative nature of tortious ones: put rather differently, in a situation where someone does work on the property of another there is a difference between the contractual duty of competence and the tortious duty of carefulness. A contractor may fail to produce work of the required standard even though all proper care has been taken, simply because the standard required by the contract may demand more than the exercise of reasonable care to avoid harmful consequences. This is obvious where the contract expressly provides for the (higher) standard of workmanship required, but it is suggested that the position is essentially the same where an implied obligation to carry out work with due care and skill is involved. The number of disputes about whether such an implied standard has been met when there is no issue apart from the (allegedly) defective nature of the work done must surely provide some substantiation for the existence of a fairly widespread assumption that such implied duties have, at least some, relevance to the situation where the essence of the dispute is effectively "has the contractor earned his price"? This, it is suggested, is the context into which issues of substandard workmanship most naturally fit.

9 For example, where a contractor is engaged to renew the drains to a house, some damage to the driveway beneath which they run is inevitable, and identifying the point (if indeed there is one to be identified) at which this "inevitable" damage ceases so that any additional damage might possibly be classified as damage to other property attracting tortious liability would be a far from easy task. By contrast, where the contractor incompetently drives a digger into the garage demolishing it and destroying the contents the case for tortious liability will be hard to resist.

10 It goes without saying that the householder will be out of pocket if the work has been so badly done that it needs to be redone (except in the wholly fanciful situation where the initial contractor agrees that the work is substandard, accepts responsibility for it, and undertakes to pay the costs of cure whatever they may be - this is the stuff that dreams are made of but has few connections with the real world) and that patience and temper alike will have been sorely tried but mere anxiety is unlikely to be counted as personal injury. However, were a situation to be so bad that the householder had actually been made ill by it (medical evidence would, of course, be essential, including evidence on the causal link) then there is no reason in principle why he or she should be denied compensation any more than there would be if injury had been suffered as a result of being knocked over by a JCB or by falling into a carelessly guarded trench. No doubt the forseeability of such an injury would be vigorously contested, not least because the current practices of the industry are such that, should the feasibility of a claim of this kind be established, it could be expected that a large number of claimants would jump on the bandwagon, with highly plausible claims.

11 See D \& F Estates v Church Comissioners for England [1989] AC 177; Murphy v Brentwood District Council [1991] 1 AC 398; Department of the Environment v Thomas Bates \& Son [1991] 1 AC 491. For an example of the application of this 
tort rendered of only academic interest by the presence of statutory remedies. $^{12}$ The wording of the Defective Premises Act $1972^{13}$ seems obviously inapplicable to the situation of deficiently performed repairs with which we are concerned since repair and maintenance work, unlike the construction of an extension or the addition of a "granny flat", does not fit easily within the phrase "work for or in connection with the provision of a dwelling'. ${ }^{14}$ Likewise the strategy of the indirect approach, involving a prosecution for some sort of regulatory offence, the most obvious example perhaps being that under section 14 of the Trade Descriptions Act 1968, whilst simultaneously claiming a compensation order ${ }^{15}$ in the proceedings is rather unlikely to provide the primrose path to success. Apart from any problems specific to the particular offence selected - in the case of section 14 , for example, the need for the statement to be false at the time it was made means that a simple failure to fulfil an undertaking as to the future is not caught ${ }^{16}$ - there are the pervasive difficulties associated with the stricter burden of proof in criminal cases, and the need to more scrupulously observe procedures intended for the protection of the accused which militates against do-it-yourself representation, thus increasing the costs.

If the position of the householder in relation to the contractor physically present on the property is so fraught with uncertainty, what can be said of the position of the loss adjuster and the insurance company? With the latter there is clearly a contract ${ }^{17}$ but it is for the provision of insurance services and the likelihood of its containing express provisions which would make the insurer liable for the defaults of the contractor is not high. However, according to the conventional wisdom, the absence of any express term

exception see Morse v Barratt (Leeds) Ltd [1992] Const L J 158 where the cost of repairing a negligently damaged retaining wall was recoverable from the defendants. However, the exception has yet to acquire sufficient support in the authorities to make its continued survival beyond all question.

12 For the position in respect of restitutionary remedies see infra $\mathrm{n} 51$.

13 S1: in Northern Ireland identical provision is made by the The Defective Premises (NI) Order 1975, art 3.

14 The consensus of opinion amongst text writers who bother to mention the point (and many do not) seems to be that the Act does not apply to repairs or alterations: see, eg, Stanton, The Modern Law of Tort (1994), p 361; Jones, Textbook on Torts (6th ed, 1998), p 296. In any event the point would now appear to be covered by authority: see Jacobs v Morton (1994) 72 BLR 92.

15 See Powers of Criminal Courts (Sentencing) Act 2000, ss130-1; in Northern Ireland see The Criminal Justice (NI) Order 1980, art 3.

16 Whilst it may well be the case that some builders' promises are indeed fraudulent, proving this is another matter. However, the householder's problems are much the same when an honest bodger undertakes to do work to a certain standard which is then not achieved. In either case there is almost certainly a breach of warranty and the difficulty of establishing fraud means that in reality in neither case is a successful prosecution likely.

17 There might conceivably be some doubt about this in the situation where the householder has signed up for his or her mortgage lender's insurance package, so that a single payment serves both to repay the loan and pay the property insurance premium. However, since the amount attributable to the insurance premium is invariably shown separately, it is considered that there is no real doubt that in this situation the mortgage lender is simply collecting the premium as agent for the insurance company, and that the contract with the insurer actually exists. 
accepting liability is neither here nor there because the general principles of insurance law which deal with the area of reinstating damaged property provide for the insurer to be responsible for whomsoever is selected to do the work, and so all difficulties are conjured out of existence. Unfortunately life is not that simple, especially in these days of customized financial packages at discounted prices facilitated by restrictions in the scope of the cover provided. Certainly the aforementioned principles will serve to protect some householders with policies which are subject to them, but as they are not mandatory, ${ }^{18}$ there will be other householders to whose policies they are wholly inapplicable. How many there are in each category is virtually impossible to determine, not least because the complexity of the typical insurance contract (as distinct from the user friendly summary of cover provided to policy holders) means that even those who sell them may not be completely certain of all the legal ramifications. At the end of the day the insurance company drafts the contract but it is the court which interprets it, if matters should go so far, and it is not guaranteed that the meaning intended by the company will be the meaning found by the court. There thus remains an unquantifiable number of persons for whom the difficulties and problems outlined herein could be all too real. As it is difficult to see as a matter of first impression how there could be any contract with the loss adjuster, ${ }^{19}$ the position in relation to both insurer (in some cases) and loss adjuster (in virtually all) would appear to hinge on the possibility of there being some liability in tort but this surely cannot be any less problematic than in the case of the actual contractor.

Enough has been said to substantiate the point that the legal position of some householders who are unfortunate enough to be in the position where repairs covered by insurance are carried out in pursuance of arrangements between other parties which they have little power to influence is neither clear nor enviable, involving as it does theoretical and doctrinal difficulties about the actual nature of the legal rights enjoyed as well as the practical problems of enforcing those rights common to all. But, it may be asked, can it really be the case that this sub-group of householders have no effective rights of legal redress? If one of them were to go to court, would a judge really be obliged to inform him or her that, unless additional damage, identifiably distinct from that which necessitated the repairs in the first place, had been caused to the property, the law had nothing to offer. Such an outcome seems so bizarre that it is extremely difficult to believe that it would happen. But how is it to be avoided? Modern day judges, with a few exceptions such as the late Lord Denning, seem unlikely both by training and by temperament to adopt the stance taken by R S Wright J in Wilkinson v Downton ${ }^{20}$ when confronted with a situation with no obvious precedent which yet cried out for a remedy, especially given the example set by the Law Lords since 1983. Consequently, if help is to be provided by a more cautious and less expansionist judiciary, it may well be necessary for it to be firmly grounded in some existing body of doctrine so as to be capable of being passed off as merely a logical extension of established principles - just a further step down

18 See, infra, n 31 and text accompanying.

19 See, infra, n 48 and text accompanying.

20 [1897] 2 QB 57. 
an already well signposted road. ${ }^{21}$ The interesting question to explore is whether there exists any route by which a well-intentioned but risk averse judge could offer succour and comfort to any householder caught up in the situation that has been described, and it is to an examination of that issue that we now turn our attention. But first a few words should be said on the attractions of a rather different approach to the matter, namely avoidance.

\section{The Avoidance Strategy}

It is trite but true that the best way of avoiding the dangers that lurk in a swamp is not to go anywhere near it in the first place. In the present context that means that the householder should avoid having to confront the difficulties alluded to above by ensuring that there is a direct contractual relationship with the person(s) undertaking the repairs so that the situation is no different from that of anyone paying for the work out of his or her own pocket. Of course, any householder affluent enough is fully entitled to elect to fund the repairs personally, foregoing any available claim to an insurance indemnity, although this seems a rather unlikely scenario. ${ }^{22}$ However, in a considerable number of instances no such choice will be available and if the householder wants the work done expeditiously s/he will be dragged into the swamp, willing or not. It is not unlikely to be the case that the combined effect of the urgency of the repairs ${ }^{23}$ and the insufficiency of available funds will compel the householder to fall in with the insurer's game plan. This will likely involve the insurer dealing with the building contractor directly, or through the services of an intermediary such as a loss adjuster, rather than handing over a cheque for the assessed cost of repairing the damage and telling the householder to get on with making the necessary arrangements. ${ }^{24}$

21 It is conceivable that with the advent of the Human Rights Act the pendulum is starting to reverse direction once again though the extent to which these principles will serve to impose novel substantive obligations on private individuals cannot be said to be free from doubt.

22 Some policy holders may well have no choice about the adoption of this strategy since their insurers may only be willing to indemnify them against the actual costs of doing the work once it has been carried out and an invoice submitted. If so, whatever financial problems they face, they will at least be spared the difficulties discussed herein.

23 The practical significance of the fact that the situation with which we are concerned involves repairs should not be lost sight of. It is an obvious truism that property insurance cover is designed to protect against the expense of repairs necessitated by natural forces or accidental damage: it is not designed to finance the addition of a conservatory or the installation of double glazing. Hence the sort of work for which it pays has a certain degree of urgency about it. When all that is involved is the replacement of a perfectly sound wooden window with a double glazed uPVC unit, the householder who is unhappy with the financing of the transaction can perfectly easily postpone the work until arrangements can be made that are more congenial. But the householder faced with a roof stripped of half its slates, a main drain blocked by encroaching tree roots, or a fire-gutted kitchen, does not enjoy the same luxury. It is necessary to begin remedying the situation as soon as possible, and, if the damage is extensive, the cost of doing so may be such that the householder has no option but to place the matter in the hands of the insurers and abide their decisions as best s/he may.

24 Or worse, informing the householder that the money will be released once evidence is furnished that the work has been satisfactorily completed! 
Thus, while the avoidance strategy may be available in a limited number of cases, usually involving relatively modest repair costs, it can certainly not be used to conjure the problems identified above out of existence.

Assuming this to be so we can now turn our attention to considering in more detail what legal rights the householder in these circumstances might conceivably possess. As our standard scenario involves an insurer, a loss adjuster, and a building contractor (although the middle party is not essential), it is proposed to consider the potential liabilities of each in turn, beginning with the insurer. ${ }^{25}$

\section{The Insurer's Position}

The ordinary man or woman in the street would almost certainly expect that if an insurer chose to discharge its responsibilities by arranging for repairs ${ }^{26}$ to be carried out, then it had an obligation to see they were done properly. At first glance, moreover, the law would seem to concur. The standard works on insurance law $^{27}$ are in agreement on a number of propositions: (1) the primary obligation of an insurer is to pay a money indemnity and there is no right to effect repairs as such $;{ }^{28}$ however, (2) the contract may give the insurer such a right; and if it does (3) the insurer is responsible for seeing that the repairs are done properly, and is responsible for those engaged to do the

25 The objective of this article is to explore the rights of the householder to redress. Accordingly no attempt will be made to deal with any issues arising in respect of rights of contribution or indemnity between these various parties, although such rights would certainly exist if liability did, usually against the contractor as the party most likely to be primarily responsible. Whether they would be of any more use to a powerful player like an insurance company than to a relatively weak consumer may be a matter of some doubt.

26 In insurance terminology this goes by the name of "reinstatement".

27 Clarke, The Law of Insurance Contracts (1989), pp 590-597: Ivamy, General Principles of Insurance Law (6 ${ }^{\text {th }}$ ed 1993), ch 45.

28 See, eg, Ivamy, op cit, at p 483: "The liability of the insurers to make good the loss under the policy is a liability to do so by a payment in money. Though any other mode of discharging their liability may be substituted with the consent of the assured, they cannot, without his consent, insist on making good the loss by what is usually known as reinstatement, $i e$ by replacing what is lost or repairing what is damaged." Clarke expresses the same idea, though in a formulation which chimes rather better with the commercial reality that it is the insurer who draws up the contract and who decides whether or not to include an option for reinstatement. The insured is basically restricted to deciding whether to take it or leave it. Thus "Reinstatement is generally an option given to the insurer, rather than the insured, and except when given by statute, that option is available only if expressly given by the contract of insurance." (Clarke, op cit, p 590). The reference to a statutory obligation to reinstate is a reference to the Fires Prevention (Metropolis) Act 1774, $\mathrm{s} 83$ which gives to certain persons with an interest in the property the right to insist on its being reinstated (to the extent that the available insurance money will allow). The reason for this provision, which is restricted to fire damage, was apparently to act as a disincentive to property owners burning down their own buildings in order to collect the insurance money - a practice both seemingly prevalent in the $18^{\text {th }}$ century and, in the then state of forensic science, difficult to prove. The Act does not apply in Northern Ireland and the equivalent legislation, the Accidental Fires Act (NI) 1944 contains no similar provision. 
work. $^{29}$ If matters rested here, then there is no doubt that the problem this article claims to be addressing would not exist, at least in the form identified. It would be nihil ad rem that most insurers certainly do not behave as if they had responsibility for the contractor, for it is a truism of life that what is the law does not always correspond with what popular opinion believes it to be. Nor would it matter that few worldly-wise householders would derive much comfort from the knowledge that responsibility lay with the insurer, knowing full well the enormity of the problems (and potential cost) involved in making a reluctant or resistant insurer shoulder it, and thus the unwisdom of even trying in the first place. This, after all, would be merely another variant on the theme of a clear legal right with limited or no practical value, analogous to the position with respect to builders, discussed at the outset. However, whether fortunately or otherwise, the picture is not as simple as this for on closer examination it appears that the background is not what it looks like on cursory examination.

There is no doubt that there is case law authority ${ }^{30}$ to support the proposition that insurers who have a contractual option to reinstate, and who chose to exercise it, are "responsible for the manner in which the rebuilding or

29 Ivamy, op cit, p 487. See also Clarke, op cit, at p 594: "To appoint a competent contractor to undertake the reinstatement is not enough: the insurer is responsible for the quality of the contractor's work. The insurer has promised, not to arrange reinstatement of the property by someone else, but to reinstate it. The work must be done and done properly." Unfortunately, no English or Commonwealth authority is cited in support of these statements, certainly none which establishes these propositions to be of universal application. While from the householder's perspective it would be ideal if they were, the problem of principle, that a right derived from contract depends on the terms of the particular contract giving birth to it, is an issue which is conspicuously not addressed in these remarks. What about a contract which actually does contain an express promise to arrange reinstatement by someone else? On what basis is an obligation different from that expressly undertaken to be imposed on the insurer? Of course, if it were possible to show that departing from the position stated by Clarke must necessarily be unfair to the insured in all cases, then it would be feasible to make the argument that the responsibility of the insurer to answer for the contractor doing the work was a rule of law, rather than simply a contractual term. Even then, however, in the absence of statutory entrenchment (the existence of which is certainly not ackowledged), contracting out ought to be possible. (The Unfair Contract Terms Act 1977 does not apply to insurance contracts.) After all that was precisely the position in respect of contracts of sale until 1973. But it would not in fact be possible to show that it must necessarily be unfair to an insured to contract for cover on terms which provide for a different allocation of responsibility from what can be called the standard pattern. If we take the example of an insured who is offered a $25 \%$ reduction in premiums in exchange for accepting a different allocation of responsibility in respect of the contractor in the event of repairs becoming necessary, it is far from clear that such a term must disadvantage the insured and consequently be outlawed. In the real world many people never have occasion to claim on their property insurance. It is far from clear that the law ought to insist on them paying more than they feel they need, or want to, for something they may never need to use. This must be even more the case when there is no question of the state having to step in to pick up the bill in so far as the individual has not made provision for it.

30 Robson v New Zealand Insurance Co Ltd [1931] NZLR 35; Samuels v Illinois Fire Ins Co 354 SW 2d 352,359 (1961). 
reinstatement is carried out. Thus, if, owing to bad workmanship, the work has to be done over again by the assured, they are liable to him for the expense to which he may have been put ..."31 The source of this obligation, since it is not statutory, must be an implied term in the contract: the sources of the confusion caused by it are the unspoken assumptions that it must necessarily be the same term in all insurance contracts of the same type and that there will be no express term inconsistent with it. These may have been perfectly natural assumptions to make at the time the authorities first establishing the proposition were decided. In a world where only the Royal Mail delivered letters and packets, where all telephone services were provided by Post Office Telephones, all high street banks kept the same hours, and most men of the same social class dressed in a virtually identical fashion, it would have seemed natural that there should be only one version of a particular type of insurance contract, and consequently only one formulation of the implied term to be included in it. But, of course, that world is not the world in which we now live. In particular, banks and insurance companies have been obliged to reconsider the somewhat superior attitude which they used to adopt and to accept that the services they provide are in essence the same as those provided by the grocer or the tailor - the fulfilment of the wishes of the customer at the price the customer is able, or willing, to pay. This in turn has led to a recognition that, as in the case of clothes or crockery, there is scope for a range of products of differing quality at different price levels. The modern insurance company provides a range of insurance products at different prices, and even in the context of property insurance lower premiums may be obtained in return for higher excesses and/or restrictions on the scope of the cover. In this world the assumption which underpinned the imposition on the insurer of the obligation to answer for the contractor looks rather less like "something that goes without saying" 32 in all cases. And while, the law being famous for its attachment to the passé, such might well remain the "default" position, coming into operation when no other provision has been made, does the law actually require the same outcome where a different one has been expressly stipulated for? In purely commercial terms there can be no more objection to offering a range of insurance products providing different levels of cover at different prices than there is to offering a range of waterproof clothing with diverse resistance to the elements at different prices. Provided it is made clear what is on offer for the price being asked, the individual customer has the right (and the responsibility) to select the product which best matches with his or her particular needs and available resources. The law of sale accepts that an item is not necessarily lacking in "satisfactory quality" because a better one can be had elsewhere. The crucial question is, does the same logic apply when the product being bought is insurance cover? Can the insurer stipulate in the insurance contract for a different outcome than would be provided for by the conventional position? In so far as this rests purely on a term to be implied in the contract the answer in principle must be yes. It is trite law that an implied term cannot contradict an express term. ${ }^{33}$ Implied terms may differ in the amount of resistance they show to being displaced, in other

31 Ivamy, op cit, n 27, p 487.

32 Southern Foundries v Shirlaw (1926) Ltd [1939] 2 KB 206.

33 See any contract text, eg, Anson's Law of Contract (27 th ed, 1998), at p 145. 
words, some implied terms are more easily avoided than others, but, in the absence of legislative copperfastening, ${ }^{34}$ all must yield to a sufficiently expressed contrary intention in a particular contract. We therefore need to ask whether matters do depend purely on the terms of the particular insurance contract or whether other legal provisions might intervene.

The obvious place to look for some overarching provision restricting the contractual freedom of insurers is in the legislation relating to unfair contract terms. The Unfair Contract Terms Act 1977 does not apply to insurance contracts at all. ${ }^{35}$ It can be argued ${ }^{36}$ that it does apply to a contract of reinstatement, which is a different kind of contract from an insurance contract, even if it is born out of one, but, even if correct, all this means is that the requirement of reasonableness will apply to any purported exclusion or limitation of liability in a reinstatement contract. ${ }^{37}$ Such clauses can be reasonable, even in a consumer context. If the restriction is in effect bought by the insurer through charging a lower premium than would otherwise be the case, then it is suggested that it is highly likely it would be reasonable. Anyway, if there is no contractual duty of reinstatement, because the insurance contract does not provide for one in the first place, then, it is submitted, the issue simply cannot arise. ${ }^{38}$ As to the Unfair Terms in Consumer Contracts Regulations 1999, regulation 6(2) specifically provides for not assessing the fairness of a term which defines the main subject matter of the contract or relates "(b) to the adequacy of the price or remuneration, as against the goods or services supplied in exchange." It is difficult to believe that a provision which defined the extent of the cover the insurer was providing in return for the premium would not fall within one or other of these provisions. There seems little here to constrain the ability of insurers to write insurance contracts under which they accept less responsibility as a quid pro quo for lower premiums.

It might be thought no exaggeration to say that the present position is rather lacking in clarity. If the obligation on insurers exercising an option to reinstate to answer for the sins of contractors is purely derived from an implied term in the insurance contract, as seems to be the case, then it is perfectly possible that an express term conferring a right to reinstate without such responsibility would be acceptable to the courts on the basis of a straightforward application of the general principle that an express term prevents the implication of an inconsistent implied term. But in any case it was noted above that, as the right to opt for reinstatement must be expressly given by the contract, insurers can easily avoid it by including no provision for it. ${ }^{39}$ It is not inconceivable that they can go further. It is generally accepted that the insured is under no duty to spend the insurance money on repairing the damage, unless the contract provides to the contrary, which it can. ${ }^{40}$ If insurers can oblige the insured to expend the money on repairs, can

$34 \mathrm{Eg}$, as in the case of the terms implied in the Sale of Goods Act 1979, ss12 -15.

35 Sch 1, para 1(a).

36 See Clarke, op cit, n 27 at p 594.

37 Presumably by virtue of $\mathrm{s} 3$.

38 A fortiori, surely, where the contract expressly disclaims any intention to assume an obligation to reinstate.

39 Supra, n 27 and text accompanying

40 See Ivamy, op cit, n 27 at p 490. 
they go one step further and acquire the contractual right to arrange for these to be done on the insured's behalf? If this were permissible, it would allow for what amounts to reinstatement without having to provide for an express option to reinstate in the contract. This looks like avoidance, which of course it is. But it might be thought that an insured who bought a policy knowing it contained such a provision on the basis that it provided cheaper cover than other options would not be in the strongest position to complain. There is nothing inherently objectionable in allowing people to buy indemnity insurance (for their own benefit) which provides a lower level of cover in exchange for a reduced premium.

The upshot of all this is that there is no single position in respect of the insurer. Some householders will have cover containing a conventional reinstatement option for the insurer. They at least will have that degree of comfort which can be derived from knowing that if the contractor makes a hash of things they can look to their insurer to pick up the pieces. ${ }^{41}$ But for an unquantified, and quite possibly growing, number of others the position will be different. They will be covered under policies which are explicitly intended not to impose on the insurer the concomitant obligations of a duty to reinstate in conventional form. What their rights are can only be determined on a case by case basis by looking at the terms of their particular insurance contract, for as Clarke puts it: "The legal basis of the insured's rights with regard to reinstatement is found in the contract. . . ."42 Those contracts will have been drawn up by the insurers with their own interests primarily in mind. Moreover, in so far as the objective has been to avoid the consequences of the conventional position, insurers would seem unlikely to concede readily that their attempts had failed. Litigation against insurers with a vested interest to protect is not a course to be undertaken lightly or inadvisedly; it would certainly not be undertaken cheaply. In the overwhelming majority of cases of the sort with which this article is concerned the only sensible advice to offer to a householder whose insurer is categorically refusing to accept responsibility for the contractor's misdeeds is to let the matter drop. Any other course of action would be too expensive for all but the wealthiest to contemplate.

If contract is so problematical a basis for liability, does tort offer an easy escape route? Regrettably, the answer is "no". In any reasonably conceivable situation the insurer will be at best an indirect cause of loss directly attributable to the incompetent activities of the building contractor, therefore any liability to which it is subject cannot be for harming the plaintiff (since it has not done so) but for failing to prevent another from harming the plaintiff. It is well known that the law displays considerable

41 The extent to which this is a comfort will be tempered not only by knowledge of the problems mentioned earlier but also by the fact that, in the case of a building, exactly what is required to achieve "reinstatement" is capable of providing ample scope for disagreement. As Ivamy puts it: "In the case of a building, however, it would be unreasonable to demand from the insurers a literal performance of their duty, for it is impractical to restore every minute detail of a building. They will therefore have fulfilled their duty when the restored building is substantially the same as before." Ivamy, op cit, n 27 at p 486, emphasis supplied.

42 Clarke, op cit, $\mathrm{n} 27$ at p 594 
reluctance to make A liable to B for harm caused to B by C. ${ }^{43}$ As Winfield and Jolowicz used to point out this reluctance is even more marked when the loss involved is simply economic loss ${ }^{44}$ as will be the case with incompetently done repairs which simply need to be done again properly. ${ }^{45}$ Thus, the chances of imposing liability for negligence on the insurer are miniscule. ${ }^{46}$ Liability for intentional wrongdoing would be another matter but it is of the nature of artificial legal persons to be devoid of such human failings as spite, malice or intention to injure. Were such motives to inform deliberate conduct aimed at the plaintiff the most likely legal response would be that the perpetrators were not acting in the course of their employment, consequently their employer was not vicariously liable for their activities, whatever might be the position in respect of their personal responsibilities.

\section{The Position Of The Loss Adjuster}

It can hardly be the occasion of great amazement that when a loss adjuster appears upon the scene in the sort of context with which this article is concerned he or she invariably does so at the behest of the insurer. ${ }^{47}$ This obviously must be so if he or she should happen to be the insurer's employee but from the householder's perspective the situation will appear little

43 Except, of course, where A is C's employer and therefore vicariously liable for his conduct. For examples of the legal response in non-employment situations see: $P$. Perl (Exporters) Ltd v Camden London Borough [1984] QB 342; Smith v Littlewoods Organisation Ltd [1987] AC 241; Topp v London Country Bus (South West) Ltd [1993] 1 WLR 976.

44 Winfield and Jolowicz on Tort (14th ed, 1994), pp 105 et seq. Although there is no reason to believe that this proposition is still not in essence accurate, the passage appears to have been excised from the 15th ed (1998).

45 A not unlikely scenario involves work which is functionally sound but deficient in appearance, which is reflected in some consequential diminution in the value of the property. The householder is faced with the choice of leaving things as they are and accepting a devalued asset or expending additional sums of money to remedy the devaluation. Either way he or she is, at least initially, out of pocket. Whether this remains the case depends on the behaviour of the property market.

46 It is suggested that this is so even after the degree of post-Murphy relaxation apparently introduced by the decisions of the House of Lords in Spring, Henderson v Merrett, and White. This point is considered more fully below (see ns 54-56 and text accompanying) and it is not proposed to duplicate that treatment here.

47 A householder is very unlikely to engage the services of such a person unless his or her insurance company has already done so. Even then the householder will probably only see the need for his own loss adjuster in situations of very substantial loss, for example, where a house has been subjected to flood damage or a collapsing tree has destroyed the roof with consequential damage to all upstairs rooms. In this sort of case the scope for argument about what needs to be done and how much it should cost are such that the householder without professional support is very likely to be at a substantial disadvantage and may well end up recovering significantly less than the full extent of the loss. The householder will, of course, have a contract with his or her own loss adjuster but the task of this individual, like that of a medieval champion, is simply to fight the battle on the householder's behalf; all that he or she can basically do is to ask the same questions and make the same representations that a better informed householder might have done personally but with a rather better prospect of achieving a more favourable outcome by the skilled deployment of his or her specialist knowledge. 
different where the loss adjuster is in business on his or her own account. In either eventuality the loss adjuster's contract must surely be with the insurer, not the householder, so that any relevant obligations whether as agent or servant will be owed to the insurer either as principal or as employer. Chief among these, indeed the primary reason for his or her involvement, will be the task of making sure that the insurer's obligation to indemnify the householder against the risk which has eventuated is discharged at the lowest possible cost. After all that is basically what the job is all about. But in addition, whether as employee ${ }^{48}$ or agent, ${ }^{49}$ he or she will be subject to legal obligations which require both concern for the interests of the person who engaged him or her and the avoidance of conflicts of interest. It is far from easy to see how it would be possible to introduce into this situation any meaningful contractual obligation owed to the householder. The law is most unlikely to imply one since it would be difficult to formulate something which successfully avoided all conflicts of interest, while any that were expressly assumed (especially if the employer did not know about them, which it almost invariably would not since it is exceedingly difficult to envisage consent being forthcoming from an informed employer to anything of any use) would be virtually certain to fall foul of the prohibition against making a secret profit. ${ }^{50}$ For these reasons, it is considered that there is no reasonable prospect of a satisfactory solution for the householder being reached via the contract route so that it is necessary to look elsewhere. Elsewhere, of course, means the law of tort. ${ }^{51}$

48 See Deakin \& Morris, Labour Law (2nd ed, 1998), ch 4.

49 See Goode, Commercial Law (2nd ed, 1995), p 176 et seq: and for more detailed treatment Bowstead \& Reynolds on Agency (16th ed, 1995), ch 6.

50 In the real world it is not very likely that the loss adjuster would be prepared to assume an obligation without any form of recompense. If this is provided, it is suggested it triggers the rule against making a secret profit. If it is not provided, then what consideration is supplied by the householder for the promise of the loss adjuster? In the absence of consideration there can, of course, be no contractual obligation absent a deed, and that is an unlikely eventuality.

51 It is considered that there is no realistic possibility of achieving a remedy via the third leg of the obligations stool, ie the law of restitution. Failing to confer a promised benefit, eg a repair job properly done, does not look much like "enrichment by subtraction" (to adopt the Birks dichotomy) being more a failure to add than a taking of something that was already there, although it is certainly possible to see things differently. And, of course, whether it is "enrichment by wrongdoing" is the very question that has to be answered, so that a remedy founded on this basis would be entirely self-referential. From the consumer perspective it might appear that any trader who fails to provide value for money has been enriched at his or her expense, but whether that enrichment is unjust must depend on whether there is any legal obligation to charge only a fair price for the service provided. It is incontrovertible that in the present state of the law there is not, and since what is value for money is very much a matter of subjective judgement reflecting the personal priorities and values of individuals, it is rather difficult to believe that this can ever become the law in a democratic society, in particular, a democratic capitalist society. Furthermore, if this were to be the law, then at a stroke much of the law of contract would be rendered redundant since the obligation to provide fair value would be incompatible with many of the rules which set out to define what the obligation undertaken is. Whatever the future may hold, it is pointless to seek for a remedy capable of present deployment in this branch of the law. 
Unfortunately, there seems little by way of comfort to be obtained from this quarter either. Precisely the same considerations apply in the case of the loss adjuster as in the case of the insurer: the harm occasioned is likely to take the form of economic loss and the effective cause of it is unlikely to be traced beyond the substandard work of the contractor. Yet there are arguments to be advanced for distinguishing between the situation of the insurer and that of the loss adjuster - certainly when the latter is an independent third party engaged to exercise local control of matters on the insurer's behalf. After all, it will usually be the loss adjuster who has actually selected and engaged the contractor; and it will likewise usually be the loss adjuster who negotiates with the contractor about the extent of the necessary work and the costs involved. This closer degree of involvement with the actual culprit can be argued to justify the imposition of a more onerous tortious duty on the loss adjuster than is appropriate for the insurer. But although the argument can be made, it is suggested that it is unlikely to find much judicial favour even in the seemingly more relaxed atmosphere prevailing after the trio of Lords' decisions in Spring, Henderson and White. Anyway, the extent of any relaxation should not be over estimated. ${ }^{52}$

Several factors combine to suggest that, with the possible exception of certain fairly restricted circumstances, ${ }^{53}$ this area is not the next one scheduled to be the site of some modest expansion in liability. First, the policy arguments for singling out this particular category of intermediaries and subjecting them to a more stringent liability than others would face do not appear particularly, or indeed at all, compelling. Certainly there seems no reason why any householder should be disadvantaged for making use of the insurance protection which has, after all, been paid for but to provide a remedy against the loss adjuster may be considered to be placing such a

52 See, eg, Williams and Reid v Natural Life Health Food Products and Mistlin [1998] 2 All ER 577 for a recent reaffirmation that cautious pragmatism is still very much the guiding philosophy.

53 The argument for the existence of a duty is at its strongest if the loss adjuster has deliberately engaged the services of an incompetent contractor known to be likely to produce substandard work. The moral attractiveness of the law's adopting a position which permits one person to save money by subjecting another to an obvious risk of financial harm is not particularly strong, and it is possible that if this were the situation liability might be imposed, although the matter is far from certain. After all, in the context of trade competition the law allows similar flagrant disregard of the interests of others without possibility of redress, and even conduct intended to inflict financial harm is permitted. Yet there is a tenable distinction between what one may legitimately do in the course of attracting custom to one's own business (even though, by definition, this means that it, and its concomitant financial reward, is denied to someone else) and what one may legitimately do to minimise the costs of providing a service to one who is already a customer (of the insurer) and who has already paid to have the benefit of that service. In any event, the likely scope of protection would not be all that great. Proof of actual knowledge (or its closest relatives) must surely be required of the plaintiff in order to justify imposing the duty, for otherwise the loss adjuster would be responsible simply because he had engaged the contractor (in effect, vicarious liability), and the obstacles that this requirement would place in the way of success would be considerable. It would not seem likely that situations in which it is possible to prove that a known incompetent was engaged to undertake a task will occur with great frequency. 
householder in an unduly advantageous position in comparison with those who have to make their own arrangements. Secondly, making a remedy in tort available against the loss adjuster would seem to involve a significant advance beyond the modestly expansionist position demonstrated by such decisions as those of the Law Lords in Spring, ${ }^{54}$ Henderson $^{55}$ and White. ${ }^{56}$ Whatever the disputes about the principle(s) forming the foundation of those cases, and the wisdom or otherwise of the actual decisions in them, there can be little doubt that in each one the defendant was the party who played the leading role in bringing about the damage complained of, even if other actors subsequently appeared on the stage before it happened. In none of those cases were the actual victims, or the third parties whose actions were the immediate cause of the damage, charged with any particular responsibility to avert the harm which ensued. ${ }^{57}$ In contrast, the loss adjuster who provides clear and unambiguous guidance is surely justified in assuming that the contractor will carry out the task properly in conformity with it. So that where this does not happen it will be normal to see the contractor, not the loss adjuster, as having played the leading part in bringing about the householder's loss. Extending tortious liability for economic loss to a mere supporting actor in the drama would represent, as already indicated, a marked extension of the reach of liability. It may be doubted whether judges who are just recovering from the effects of the prolonged retreat that was necessitated after the untenable nature of the position adopted by their predecessors in the infamous Junior Books decision ${ }^{58}$ had become apparent would wish to risk having to endure the same process again as a consequence of having been fired by a similar overly enthusiastic approach to extending the boundaries of liability.

A third factor which makes the case of the loss adjuster distinguishable is the fact of the existence of a tangible source of the loss in the shape of the deficient repairs, so that the situation is far more akin to economic loss caused by a defective product than was the case in any of the aforementioned House of Lords decisions which appeared to signal an end to "the retreat from Anns" era. ${ }^{59}$ And it was, of course, in cases of economic loss caused by defective products, to wit buildings, that the Lords advanced the "no

4 Spring v Guardian Assurance plc [1995] 2 AC 296.

55 Henderson v Merrett Syndicates Ltd [1995] 2 AC 145.

56 White v Jones [1995] 2 AC 207.

57 There is, of course, a general responsibility on victims to have regard to the need to safeguard themselves against the normal perils of human existence which is enforced by the doctrines of contributory negligence and volenti non fit injuria. Similarly, the law expects the taking of reasonable precautions against obvious risks of becoming the means by which the consequences of negligent behaviour are transmitted to the ultimate victim. But none of the more recent cases have raised any issues which require these matters to be seriously explored.

58 Junior Books v Veitchi Co Ltd [1983] AC 520. This decision has been subjected to considerable villification but see below $\mathrm{n} 85$ and text accompanying.

59 It would surely be nonsensical to regard the reference in Spring as such simply because it was in writing since the issues of legal principle would be exactly the same if it had been given orally or sent electronically. There might be more to be said for so regarding the will in White but, of course, the whole point of that case was the fact that no valid will expressing the final wishes of the testator ever came into existence, so the issue is irrelevant. 
recovery for mere economic loss" rule in its most stringent form. ${ }^{60}$ That being so it is surely unlikely to be amongst the first areas to see radical change. ${ }^{61}$ But quite apart from these grounds, there is the additional problem of identifying what is substandard performance in a case like that of the loss adjuster. Those cases in which the courts have more recently shown themselves prepared to make modest extensions to the boundaries of liability, notably by reinterpreting the reach of the Hedley Byrne principle so as to apply it to the provision of services, either involved purely the provision of professional services ${ }^{62}$ or else simply the supply of information. ${ }^{63}$ Thus there was no need to confront any difficulties about what was the appropriate standard of care to be applied since, once the nature of the task to be undertaken had been sufficiently identified, the only question to be answered was whether it had been performed to a proper standard for a person undertaking that task. No doubt the same approach would serve in the case of the loss adjuster were the issue to be whether he or she had agreed to work being done in a form which posed dangers of personal injury or damage to other property, but of course that is not the situation with which we are concerned. In the context of making property repairs there are numerous ways of achieving the same result. For example, even in a very simple case like a broken window the range stretches from sticking clear polythene sheeting over the hole with adhesive tape to replacing the entire window with a state-of-the-art triple-glazed sealed unit. The particular course adopted will depend on various factors including the amount of money available to pay for the repair, personal preference, knowledge of the available options and so on. The intrusion of these additional considerations substantially complicates the task of evaluating whether or not the conduct of the loss adjuster has been negligent. In fact negligence does not seem to be the real issue involved in the case of the loss adjuster: the crux of the matter rather appears to be whether the householder has been provided with the appropriate level of indemnity for which he or she has paid. ${ }^{64}$ Taking all these matters into account the prospects of the householder obtaining redress by a tort claim against the loss adjuster look distinctly unpromising. Having struck out twice, therefore, it remains to consider whether proceedings against the contractor offer any better prospects of success.

\section{The Position of The Building Contractor}

To any layman it is obvious that the building contractor is the party responsible for any deficiencies of workmanship, either through personal

60 In D \& F Estates and Murphy v Brentwood District Council, supra $\mathrm{n} 11$.

61 The fact that a version of the rule is now enshrined in statutory form in s 5(2) of the Consumer Protection Act 1987 [in Northern Ireland art 8(2) of the corresponding Order] is surely another reason why early change is not to be expected. To produce a situation in which the common law claim is available when a remedy is denied under the reforming legislation that was introduced because of the supposed inadequacies of prior protection looks distinctly odd. The fact that the law is riddled with inconsistencies is no reason for deliberately adding to their number.

62 White v Jones, Henderson.

63 Spring.

64 Or put more bluntly has he or she been ripped off? 
incompetence or through being responsible for staff who have performed the work in a substandard fashion. Yet if the contractor's practical responsibility is clear beyond argument, the same is far from true of his legal responsibility. On any conventional analysis of the contractual connections the builder is several stages removed from the householder, being engaged by the loss adjuster who in turn is contracted to the insurance company which alone has a contract with the householder. ${ }^{65}$ As already pointed out, ${ }^{66}$ there will be no peculiar problems with establishing liability in tort where incompetent work causes personal injury or damage to other property but this will be of no assistance in the far likelier situation concerning us here of only economic loss being suffered. If the work is simply so badly done that it requires to be completely or partially redone ${ }^{67}$ then it appears the householder's loss is, on the authority of $D \& F$ Estates v Church Commissioners for England, irrecoverable in tort. Yet the claim that common justice requires that a householder who is prejudiced by the incompetent performance of work by a contractor engaged on behalf of his insurers should not be left without a remedy would also seem to be most fairly satisfied by providing that remedy against the contractor. As suggested earlier, ${ }^{68}$ to do otherwise might well place such householders in a more advantageous position than those who had a direct contractual link with the culprit. While there is nothing ipso facto objectionable about this (the law is frequently less than even handed in the way it distributes its favours), it is not necessary to do this in order to avoid the injustice that the complete absence of a remedy would entail, and there is no merit in creating an unnecessary anomaly. ${ }^{69}$ If the primary contract is not made with the householder, and it is suggested it is not, then the remaining possibilities appear to involve imposing liability on the builder via a

65 The possibility of a direct linkage via a collateral contract will be explored further below: see ns 70-75 and text accompanying.

66 See ante $\mathrm{n} 7$ and text accompanying.

67 Or completed - it is a commonly recurring theme in complaints against property repairers that work is either left unfinished or that it has at least required the expenditure of considerable effort to get the contractor to apply the finishing touches. The commissioning householder has, of course, the leverage provided by the ability to withhold payment until the job is finished. If the contract is entire, as in Cutter v Powell (1795) 6 TR 320, payment would not be due until performance were complete and although this is subject to the doctrine of substantial performance (see Hoenig v Isaacs [1952] 2 All ER 176) it will generally be a lot simpler for the contractor to obtain payment by finishing the work than by litigation. The householder in the situation with which we are concerned may well not be able to avail of this weapon, unless the contractor has been engaged on terms which make the right to payment conditional on the householder's approval of the standard of the work done. For a variety of reasons, some of which were explored earlier, this is not all that likely to be the deal done.

68 See ante ns 53-54 and text accompanying.

69 It is true that the householder who is not commissioning the work does not have the opportunity to vet the contractor for competence and solvency so as to minimise the chances alike of any complaint arising at all and, should one do so, of being unable to obtain satisfactory redress in respect of it. It could, therefore, be argued with some plausibility that the law would be justified in offering an enhanced level of protection to those who, through no fault of their own, were unable to protect themselves in the way that others were. However, that argument is not adopted here. 
collateral contract or by imposing a tortious duty of care. Let us now consider these possibilities.

At first glance the collateral contract approach appears to have distinct possibilities since it was the basis of the successful claim in Charnock v Liverpool Corporation ${ }^{70}$ where the Court of Appeal ruled that the fact that the garage repairing the plaintiff's car had a contract with his insurance company as regards payment for those repairs did not mean it did not also have a contract with the plaintiff himself in respect of the time to be taken to do them. However, further examination suggests that initial impressions may have been misleading. First, although Charnock has stood for thirty years it has not escaped entirely unscathed from the attention of the commentators, though criticism has been rather more implicit and muted than express and unequivocal..$^{71}$ Secondly, the case hardly constitutes an exhaustive examination either of the authorities ${ }^{72}$ or of the relevant policy issues. Indeed when one reads the judgments, particularly that of Harman $\mathrm{LJ}$, one is left with the distinct impression that the court considered that its time was being unnecessarily wasted on a trivial dispute in which only $£ 53$ was at stake, and that it was anxious to dispose of the case as speedily as possible. This impression does little to assist in fostering the belief that the decision was a carefully considered one not lightly to be viewed as in need of reconsideration. Thirdly, the facts of Charnock appear to differ in several significant respects from the sort of situation we have been dealing with in this article, so that even if its authority is able to withstand a determined challenge, it may yet be distinguished as inapplicable to the circumstances particularly concerning us. ${ }^{73}$ Finally, and perhaps most crucially, any collateral contract between the householder and the building contractor must surely be consistent with the contractor's obligations under the principal contract with the insurer or loss adjuster. Just as the courts will not imply a term into a contract which contradicts an express term of it, ${ }^{74}$ so it is difficult to see how they can confer on the householder by means of an implied collateral contract rights against the building contractor which are not compatible with the latter's contractual obligations to the person(s) engaging his or her services. After all, it is one thing to bind oneself to mutually inconsistent obligations but it is quite another to have such foisted upon you

70 [1968] 3 All ER 473 (CA).

71 See, eg, Treitel, The Law of Contract (10th ed, 1999), p 541.

72 Only 3 cases were referred to in the judgments and none of these was subjected to anything that might remotely be taken for exhaustive analysis.

73 Charnock himself selected the garage to undertake the repairs, informed his insurers of his choice, and in effect procured their acquiescence in it. On these facts it is perfectly plausible to argue that the main contract for the carrying out of the necessary repairs to the vehicle was made between Charnock and the garage and that the contract with the insurance company in respect of payment for them was collateral to this contract, the consideration provided by the garage being a promise to the insurers to carry out the repairs. Of course, they already had a contractual obligation to Charnock to do this but it has been the law for a long time that a promise by A to B to perform a contractual obligation which A already has to $\mathrm{C}$ provides perfectly good consideration for a return promise from B (in Charnock the promise of the insurer to pay the garage for doing the repairs): see Shadwell v Shadwell (1860) 142 ER 62, Scotson v Pegg (1861) 158 ER 121.

74 Duke of Westminster v Guild [1985] QB 688, at p 700. 
by operation of law, especially in a context where the contractual obligations which were expressly undertaken were unexceptionable in point of law. It may be possible for the law to tolerate a collateral contract between two parties which contradicts the terms of another contract between them ${ }^{75}$ but in such a situation the real issue is about what their actual agreement was, and the collateral contract is simply a device for evading the parol evidence rule when orally agreed terms have not been reflected in a standard form written contract. In such a situation the collateral contract may promote justice: this would most certainly not be the case if the device were used to place someone in a situation of having incompatible contractual duties to two different parties. The inescapable conclusion is surely that effective protection for the householder cannot be obtained by means of the collateral contract approach since the scope of the protection available will be entirely dependent on the terms of the principal contract in each particular case, terms of which the householder may well have no knowledge and over which he or she certainly has no control. It is therefore necessary to seek for salvation in the realms of tort.

Since we have now virtually exhausted the possible ways of furnishing the householder with a legal remedy, it would be serious indeed if the law of tort were to prove as barren of hope as the other territory we have traversed in our journey to this point. Fortunately, it can be argued that it does not and that a plausible argument ${ }^{76}$ can be mounted for a remedy in tort. This would bring the householder whose repairs are being organised by his or her insurers to a position somewhat closer to, though obviously not identical with, that enjoyed by the householder who is having to make his or her own arrangements. ${ }^{77}$ The achievement of this outcome, should the argument for tortious liability be accepted, would do something to provide a remedy for the householder who does not have one against his insurer, and also perhaps to the one who does but who finds that it is for practical purposes unenforceable.

The basis of the argument is actually absurdly simple. It starts from the initial proposition that it is axiomatic that economic loss is recoverable under the principle of Hedley Byrne $\mathrm{v}$ Heller $^{78}$ and that it is now equally wellestablished by several post Murphy House of Lords authorities, particularly Spring, Henderson v Merrett and White v Jones, ${ }^{79}$ that that principle is not confined to reliance upon statements but extends to acts and to situations where the identification of any actual reliance is distinctly problematic. The

75 City \& Westminster Properties (1934) Ltd v Mudd [1959] Ch 129.

76 Plausible but not, of course, guaranteed to succeed.

77 Whether it is preferable to have a remedy in contract or in tort is an interesting question but one that will not be pursued further here. Some of the more commonly cited distinctions, for example, the much more generous approach of the law of tort to the question of remoteness of damage seem unlikely to produce significant differences in outcome in the sort of situation on which we have been focussing throughout this article. In relation to remoteness this is true because it will be extremely unusual for genuine consequential loss to be involved, whilst the financial cost of putting right what went wrong can hardly differ according to the legal categorisation of the obligation to pay for it.

78 [1964] AC 465.

79 Supra, ns 54-56 and text accompanying. 
basis of the principle now seems to be assumption of responsibility and this seems to mean, at least according to some of their Lordships ${ }^{80}$ little more than choosing to undertake the activity which eventually produced the harm with knowledge that the plaintiff was involved in the situation and hence a potential victim should things miscarry. The next stage is to take advantage of the fact that the law exhibits a certain degree of sympathy for owner occupiers who are the victims of professional negligence, as evidenced by the fact that the negligent surveyor cases of Smith $\mathrm{v}$ Bush and Harris v Wyre Forest District Council ${ }^{81}$ stand out as virtually unique amidst the relentless tide of pro-defendant decisions handed down between Junior Books v Veitchi $^{82}$ and Murphy v Brentwood District Council. ${ }^{83}$ Obviously the decision in Murphy itself shows that the sympathy has its limits but the fact that in that case it was the nominal plaintiff's insurer who stood to gain most from a favourable decision while the defendant was a local authority - so that the case could be seen as attempting to pass on a commercially accepted risk to the general body of ratepayers in the area - may well have had something to do with the outcome. In Junior Books itself, of course, the plaintiff recovered for purely economic loss caused by careless building work. ${ }^{84}$ The general vilification to which that decision has been subjected has stopped short of actually overruling it and indeed the current fashion is to say that the actual outcome may have been correct in the circumstances ${ }^{85}$ and may be supported on the basis of the Hedley Byrne principle. By combining this authority which allows for the recovery of economic loss caused by defective building work with that in White $\mathrm{v}$ Jones $^{86}$ supporting the existence of liability in situations where the victim of loss has no obvious alternative remedy so that to deny one in tort would leave them effectively remediless, we reach the conclusion of the entire argument, namely that the contractor of our scenario does owe a tortious duty to the householder which will extend to the economic consequences, that is the costs of redoing, defectively performed work. ${ }^{87}$ Whether or not this argument will eventually prove acceptable is something that only time will tell. However, it is submitted that the argument fits sufficiently well with existing precedents, and serves to fill what is an otherwise rather curious lacuna in the law whilst generating fewer consequential problems than any of the other possible solutions that have been canvassed herein, as to be deserving of at least serious consideration. And as Lord Steyn observed in Williams \& Reid v Natural Life Health Food

80 See, in particular, Lord Browne-Wilkinson in White v Jones [1995] 2 AC 207, at pp 273-74.

81 [1990] 1 AC 831.

82 [1983] AC 520.

83 [1991] 1 AC 398.

84 It is of course true that in Junior Books itself the work was work of new construction rather than of repair but it has never apparently been suggested that this did, or should have, exercised any influence on the outcome.

85 See $D \&$ \& F Estates Ltd v Church Commissioners for England [1988] 2 All ER 992, at $\mathrm{p}$ 1013, per Lord Oliver; Murphy v Brentwood District Council [1990] 2 All ER 908, at p 919 per Lord Keith, but compare Lord Bridge at $\mathrm{p} 930$.

86 [1995] 1 All ER 691, at p 702 per Lord Goff.

87 Whether it should extend beyond that is another interesting question that will not be pursued further here, although there are persuasive reasons in support of the argument it should not. 
Products \& Mistlin: "Coherence must sometimes yield to practical justice." If the dictates of justice require that consistency of approach be sacrificed, then the current appellate panel seems happy to be inconsistent. That at least should be cause for hope.

There will, of course, be those who take the view that this is not only a contrived solution but, worse, a contrived solution to a non-existent problem. Even if they accept the argument herein that it is not nowadays the case that all householders are covered by policies which require insurers to take responsibility for contractor's failings, they would argue that this must have resulted from a conscious choice on the part of those so circumstanced. That the householders concerned must have deliberately elected for less protection, presumably for good reason, and, having made their bed, must lie in it. There would be considerable force in this contention if it could be shown that all those householders without recourse to their insurers had freely opted for this situation when they knew, or should have known, of the possible consequences. The case for intervention to rescue people from a situation of their own contrivance is not necessarily at the top of the priority list. However, it is far from clear that all those who find themselves in this situation have only themselves to blame for it in any realistic sense of that term. A good deal of household insurance cover comes as a job lot along with the mortgage. People thus end up with the cover which their lender thinks suitable, but the concerns of the lender for the safety of the security interest may not be identical with those of the householder living in the property or hoping to sell it at a profit, and making alternative insurance arrangements may be neither encouraged nor facilitated. Nor is this the only explanation for how a householder could find him or herself in the dismal situation described in this article without any real responsibility for that predicament. There are some, therefore, who both need and deserve help from a solution such as is here put forward, whether it be contrived or not.

\section{Miscellania}

For the sake of completeness three final points may be made very briefly. First, the householder whose damage results from deficiencies in the materials used rather than deficiencies of workmanly competence may have a product liability claim under the provisions of the Consumer Protection Act $1987 .{ }^{89}$ However, this will only serve to protect against damage to other property since, as pointed out above, ${ }^{90}$ the legislation specifically excludes damage to the product itself from the scope of the protection it affords. The straightforward costs of replacing defective products with sound ones would not be covered, which, as we have argued earlier, is by far the most likely explanation for the householder's losses. In any event it is not very common for such simple products as bricks, timber and cement to be found to be faulty in themselves, especially given modern quality control techniques. Where they are a source of problems, a far more common explanation is human incompetence in selecting something inappropriate to the task that

88 [1998] 2 All ER 577, at p 584d.

89 And also a claim for common law negligence under Donoghue v Stevenson subject to exactly the same drawbacks as affect the claim under the statute.

90 Supra $\mathrm{n} 61$ and text accompanying. 
has been given, or carelessness in fixing or mixing. Few householders could expect to achieve a remedy by this route.

Even fewer could expect to achieve success by using the route to which our second point refers, that is, by suing the retailer for breach of the obligations implied in a contract of sale. ${ }^{91}$ To do so it would be necessary for the householder either to have bought the materials personally or else to be able to convince a court that the building contractor bought as his or her agent. Although in the case of some small scale repairs the tradesmen undertaking them may request payment for all materials in advance, this is unlikely to be a matter of common occurrence in cases of sufficient value to justify proceedings. In addition, of course, all the remarks made in the previous paragraph about the infrequency with which things, as opposed to people, are the real cause of damage apply here also.

And lastly, any householder who encounters problems with double glazing work may be able to seek redress under the code of practice of the relevant trade association as an alternative to contemplating legal action. The number of occasions when this is likely to be relevant to the matters that have concerned us is miniscule.

\section{CONCLUSION}

It is a source of considerable amazement that difficulties which must confront thousands of people every year, ${ }^{92}$ involving not inconsiderable sums of money, not to mention the stress which victims often undergo, have so little interacted with the law that the position is as obscure as we have found it to be. Of course, widespread owner occupation with all its accompanying responsibilities is a relatively recent phenomenon. Certainly, well after the Second World War the majority of the population were living in rented accommodation so that the extent of their involvement with the problems which have concerned us herein was limited to informing the landlord and leaving matters up to him. Perhaps in the timeframe within which the law operates there has simply not been long enough to address and solve the problem, although it is difficult to give serious credence to such an explanation. But whatever the explanation for the present state of the law, continuation of this situation does not seem a plausible option. Sooner or later some person who has been sufficiently incensed by the treatment meted out to be prepared to hazard litigation, and who is able to find a lawyer prepared to act on a "no win, no fee" basis, will come forward and require the courts to answer the question which they have managed to evade up until now. It will be interesting to see how they do so!

91 Sale of Goods Act 1979, ss 13 (correspondence with description), 14 (satisfactory quality and fitness for purpose) or 15 (correspondence with sample).

92 A number likely to increase if our weather continues to worsen so that more frequent violent storms wreak more extensive damage to more property. 